\title{
MURILO MENDES LIDO PELOS ITALIANOS
}

\author{
Maria Betânia Amoroso
}

Os três textos que abrem a fortuna crítica italiana de Murilo Mendes foram publicados entre o final de 1957 e o início de 1959.

O primeiro a escrever é Dario Puccini, estudioso, crítico, tradutor e professor de literatura hispano-americana em Roma. Coube a Puccini apresentar pela primeira vez o brasileiro recém-chegado. Mesclando informações biográficas, descrição de traços físicos e comentários críticos, dá eco à voz do poeta, este sim o verdadeiro autor das ideias que informam o texto, aquele que escolhe o que apresentar como característica marcante de sua poesia.

Murilo Mendes, um dos cinco ou seis poetas brasileiros de maior relevo e de fama internacional, vive há um ano na Itália, encarregado pelo governo de seu país de ministrar curso de Literatura Brasileira na Universidade de Roma. Com paciente e juvenil entusiasmo, apesar de seus cinquenta e seis anos, Mendes aprendeu com os textos de nossos escritores mais jovens e convivendo com as pessoas a decifrar e a falar o italiano do dia a dia, sem esquecer contudo o italiano de Petrarca e de Leopardi que há muito tempo conhecia e apreciava. "Não vi e nem me encontrei com escritores italianos que gostaria muito de conhecer. E não o fiz porque antes queria saber falar italiano", me disse Mendes [... $]^{1}$.

Pela pena de Puccini, Murilo procurará, nesse primeiro momento, livrar-se de dois estigmas provavelmente excessivamente pesados e até 
então alimentados por parte da crítica brasileira: o de poeta católico e o de sua poesia como irreverente e irônica, definição devedora aos poemas publicados na década de 1930, nos livros Poemas e História do Brasil principalmente.

\begin{abstract}
Seriam suficientes seus poemas sobre a guerra, sobre os horrores da guerra [...] de Poesia libertade (sic), de 1947 para defini-lo na sua mais profunda substância. As outras definições, como a de "poeta católico", devido a sua adesão ao catolicismo e ao livro que escreveu com Jorge de Lima, Tempo e eternidade (1935), que tinha como subtítulo "Restauremos a poesia em Cristo", não passam de definições parciais, incompletas, tanto em relação a sua obra poética precedente, livre, irônica e irreverente (Poemas, 1920, e História do Brasil, 1932), quanto ao lirismo e complexidade de suas visões e imagens surrealistas do período 1941-45 (Poesia em Pânico, As metamorfoses e Mundo enigma).
\end{abstract}

Uma visão de mundo mais complexa do que a pressuposta nos poemas-piadas; uma poesia moderna cujas imagens guardam intimidade com o surrealismo: esta é a produção poética escolhida para apresentálo ao público italiano, mais presente nos livros Poesia em pânico, As metamorfoses e Mundo enigma, publicada entre 1936 e 1945. Contra qualquer relação que se venha a estabelecer entre ser católico e ser conservador, antigo, Murilo lança as frases citadas, na sequência no artigo, por Puccini: "Eu sou primeiro homem e poeta, depois católico!", acompanhada por outra, prova da sua contemporaneidade e da sua preocupação com o futuro da humanidade: "a maravilhosa notícia de hoje, a do satélite artificial"

Nesse artigo de 1957 se anuncia não só um poeta, maduro e com obra extensa como surge também o crítico de arte, ou o poeta-crítico, que é apresentado como recém-egresso de um encontro de críticos de arte realizado na cidade de Nápoles3.

O segundo texto a ser aqui comentado é de autoria de Anton Angelo Chiocchio, publicado três meses depois do texto de Puccini. Quando Murilo chega a Roma, Chiocchio já é um nome que circula nos meios

2 A conquista do espaço pelo homem é tema dominante na Itália nesse momento, tema associado inexoravelmente à ideia de progresso técnico infinito que irá dividir intelectuais e homens de partidos políticos, durante muitos anos. Italo Calvino, por exemplo, defenderá veementemente que o sentido progressista do evento só existirá se for acompanhado pela complementar expansão da consciência crítica do homem, posição muito semelhante a de Murilo Mendes. Ver a respeito Bucciantini, 2007.

3 Trata-se do Congresso Internacional dos Críticos de Arte, realizado em outubro de 1957, em Nápoles, pela Associação Internacional dos Críticos de Arte (AICA). 
ligados à divulgação da literatura e cultura brasileiras, atuando junto à embaixada do Brasil - a qual, em 1959, reconhece-o como divulgador cultural, concedendo-lhe a Ordem do Cruzeiro do Sul. Através da sua figura dá-se a ver o universo, a coxia talvez, da divulgação da literatura na Itália, com personagens em contato constante com a embaixada, à procura de verbas para traduções, sempre próximos de revistas literárias e comitês de prêmios, definindo um território menos visível, mas mesmo assim muito importante para a melhor compreensão da circulação das críticas.

$\mathrm{O}$ artigo publicado em janeiro de $1958^{4}$, anunciando a chegada do poeta mineiro, propõe dois argumentos que enunciam sua compreensão da poesia de Murilo: é contrário à vinculação do poeta aos simbolistas e ao surrealismo, sem que haja maiores esclarecimentos. O segundo argumento, porém, reitera o que já estava presente em Puccini: a forte recusa em ser classificado como poeta católico.

Apresentando-se como um destruidor de idola, é Chiocchio desta vez quem encarna a voz do poeta, preocupadíssimo em se desvincular das amarras anteriores impostas ao poeta pela crítica de seu país, enxergando na nova vida a possibilidade de novas leituras.

A abertura do artigo é muito sugestiva. Diz ele que a Itália desconhece o Brasil, culpa logo em seguida atribuída aos italianos. Contudo, continua Chiocchio, é preciso levar em conta que é um "país novo", e enquanto tal não possui ainda uma crítica literária, mas somente um conjunto de opiniões (muito diversas entre si, o que confunde o comentador estrangeiro). Essas afirmações, evidentemente, dizem muito mais sobre a compreensão do mundo literário do articulista, no que se refere a culturas em contato, do que sobre a poesia muriliana. Passado o desânimo inicial - espécie de desabafo -, Chiocchio indica suas fontes: Rossi - provavelmente Giuseppe Carlo Rossi - como fonte primeira; em seguida, Mário de Andrade, Alceu Amoroso Lima, Freitas Júnior e Sérgio Milliet.

O conjunto das citações lhe serve para descrever o modo particular de Murilo Mendes ser poeta universal (isto é, europeu) sendo intrinsicamente brasileiro. Utiliza-se da classificação dos poetas brasileiros inventada por Rossi, que os subdivide em dois grandes conjuntos: o primeiro, daqueles que sentem a necessidade de se opor à pressão exercida pela Europa sobre a cultura brasileira, da qual fazem parte os poetas românticos; o

4 “La poesia di Murilo Mendes", Nuova Antologia fasc. 1885, genn. 1958. Roma, pp. 109-12. 
segundo, dos que não sentem tal necessidade. Murilo é colocado entre os do segundo grupo.

O conhecido ensaio de Mário de Andrade "Poesia em 30", texto que inaugura um dos olhares críticos mais persistentes sobre a obra poética de Murilo Mendes, surge para realçar a particularidade do que é local nessa poesia, distanciando-a assim da expressão mais acanhada desse localismo, o regionalismo. Entretanto, o próprio "carioquismo" de Murilo, que havia sido anteriormente apresentado como merecedor de um futuro estudo por parte de Chiocchio, aparece ambiguamente censurado por revelar os mesmos traços do regionalismo provinciano. A bravata anunciada pelo crítico se desfaz sem algum resultado.

Nessa nova oportunidade de apresentação do poeta brasileiro por uma revista italiana, volta-se à questão que parece incomodar tanto Murilo, a da classificação no final da década de 1950, de sua poesia como a de um poeta católico. A veemente recusa do epíteto "poeta católico" desencadeia a busca de explicações para essa equivocada e perseverante interpretação, segundo Chiocchio. E então surgem os dados biográficos. Foram provavelmente fornecidos pelo próprio poeta, e serão explorados incansavelmente pelos interlocutores italianos (e por Murilo) ao longo dos anos. As "experiências marxistas" como parte da juventude "tempestuosa e irreverente", seguidas pela conversão ao catolicismo (e surge o nome de Ismael Nery) em 1934 e a publicação, no ano seguinte, de Tempo e Eternidade, junto com Jorge de Lima. Seriam esses os elementos que, transformados em dogmas, definiram a recepção de Murilo no Brasil, segundo Chiocchio, e que o poeta procura evitar que se repita na Itália. Para isso, interessa frisar é que essa fora uma fase, superada, e o poeta e o católico não se confundiram jamais.

Neste momento inaugural da recepção italiana de Murilo Mendes, o ensaio de Luciana Stegagno Picchio de 1959 é dos mais importantes: partindo de pressupostos semelhantes, presentes nos textos críticos de Puccini e Chiocchio, possui acentuado caráter de estudo, ao mesmo tempo se apresentando como contraponto às leituras da crítica brasileira e ambicionando marcar a fortuna crítica do poeta. Reavalia o que já fora dito e pretende orientar o que virá a ser comentado sobre a produção poética muriliana escrita em território italiano a partir de então ${ }^{5}$.

O terreno comum dessa primeira crítica parece já estar constituído. Parte do pressuposto da cristalização alcançada ao longo dos anos - que

5 "La poesia in Brasil: Murilo Mendes", Firenze, Rivista di letterature moderne e comparate, v. 12, n. 1, marzo 1959, pp. 36-52 (trad. bras. Alexandre Eulálio, Revista do Livro. Rio de Janeiro: INL, n. 16, dez. 1959). 
vão de 1930, data publicação dos poemas de Poesias, a 1946-1948, quando Discípulos de Emaús e Poesia Liberdade são criados e publicados. $\mathrm{O}$ alvo privilegiado é o já citado artigo de Mário de Andrade, tido como em grande parte responsável pela estigmatização do poeta como modernista e católico. Como nos outros dois críticos, mas de modo muito mais efetivo e propositivo, os esforços empreendidos por Stegagno Picchio parecem ter o claro intuito de desfazer equívocos que tais denominações teriam causado, impedindo uma desejada compreensão, mais livre, mais ampla, da poética e da poesia murilianas. Mais uma vez, porém, é possível perceber a voz do poeta por detrás das palavras dos críticos, fonte mais consultada para obtenção de subsídios sobre a crítica brasileira em relação à poesia, estando ele próprio interessado em se desvencilhar de possíveis estigmas críticos.

Tratava-se, portanto, de dissociar - como numa cruzada, aliás, nesse primeiro momento - a imagem de Murilo Mendes e de sua poesia da qualificação "católica", mas também negar que fosse tributária dos pressupostos teóricos do modernismo paulista de 1922, por sua vez apresentado como já superado, academizado e que seria substituído pelos poetas da geração de 45 e pelos "novos" poetas, mais capazes de aquilatar a importância de Murilo para a contemporaneidade do que Mário de Andrade, que escreveu sobre o poeta em outro momento, historicamente datado. Os poemas-piada, o neorromantismo implícito nas posições nacionalistas do grupo, o intelectualismo que acompanha a ironia dos versos modernistas, o surrealismo como vertente formadora da estética são os tópicos afrontados por Stegagno Picchio para limpar o terreno interpretativo e lançar sua hipótese: a obra de Murilo não suportaria classificações porque está sempre à procura de uma melhor realização poética que seja a mais completa síntese de suas buscas enquanto poeta; nasce assim, segundo a autora, a expressão capaz de definir a "unidade" em Murilo, devedora da associação entre vida e obra, sempre de tão forte presença, síntese tanto da poesia e da poética como também da personalidade: elegância-equilíbrio.

A expressão aponta para uma depuração dos excessos: o que era trasbordante, da biografia e dos resultados do Modernismo da fase heroica, teria sido desbastado, tosqueado. Os gestos largos e inconsequentes registrados pela biografia do poeta que lhe renderam a adjetivação de "surrealista" são associados às circunstâncias, afastandose qualquer caráter mais estruturante.

São deixados de lado aqueles episódios anedóticos da "história da vida" que compuseram sempre a biografia de Murilo, o qual sai deles como o poeta que vive por ações e gestos poéticos, em geral sendo 
isso identificado com ações que afrontam o senso comum e o bom comportamento das sociedades burguesas: abrir guarda-chuva no Municipal do Rio, em protesto a uma péssima execução musical; pelas janelas de uma sala, recomendar a audição de Mozart para o bairro que o circundava no Rio de Janeiro; o telegrama enviado a Hitler em protesto contra o nazismo, por exemplo; do catolicismo muriliano é recortado o jansenismo, tributário dessa mesma visão de primeira hora do modernismo dos anos 1920, e que, na verdade, não caracterizaria as relações do poeta com a fé. E não é pouca a importância dada por Stegagno Picchio a esse ponto, já que escolhe Discípulo de Emaús como livro central do qual fazer partir a análise para um Murilo que se configura como "futuro" em relação ao Murilo "passado", determinado pela crítica feita no Brasil. Será lido não só como um livro de princípios religiosos, mas fundamentalmente como revelador de uma poética.

Outro nome de grande importância na construção da fortuna crítica italiana de Murilo Mendes é o de Ruggero Jacobbi e com ele há uma espécie de retorno à dimensão religiosa, mas em chave diversa ${ }^{6}$.

Ao definir divisões na poética muriliana, Jacobbi explicitará clareza os caminhos de sua reflexão sobre o poeta brasileiro: a conversão ao catolicismo era central, sendo os livros publicados entre 1929 e 1945 divididos entre "poesia anterior à conversão" e "poesia da conversão religiosa e da guerra”. Embora o último bloco de poemas, escritos a partir de 1946, sejam reunidos como "poemas de restauração da forma, do retorno a Minas e da residência na Europa", parece que a leitura jacobbiana que predominará, e que irá se repetir em outros momentos da permanência de Murilo Mendes na Itália é a que associa Murilo Mendes a certo catolicismo de esquerda. (JACOBBI, 1960)

Em seu primeiro texto, intitulado "Arte e humanidade do brasileiro de Roma"7, as 'particularidades formais' da poesia aparecem associadas a "uma posição psicológica e filosófica das mais complexas, isto é, voluntariamente nutrida por contradições", maneira que Jacobbi encontra para introduzir o catolicismo especial, contraditório, de Murilo Mendes, posto lado a lado com o de outros católicos ilustres - Ismael Nery, Bernanos e Jorge de Lima. Murilo apresentando como um poeta católico,

6 Escritor, crítico literário, dramaturgo, diretor e teórico de teatro, Ruggero Jacobbi (1920-1981) manteve duradouras relações com a cultura brasileira. Chegou ao Brasil com 26 anos, integrando o grupo de profissionais italianos de teatro, convidados a patrocinar a modernização da cena brasileira, tendo vivido no país por quatorze anos. (RAULINO, 2002)

7 Il Messagero, 5-7-196o. 
mas de um catolicismo propenso ao abismo, ao apocalipse, aos extremos. O que, por um lado (no ângulo mais privado da obra), se manifesta como obsessão do pecado, insurgência contínua de satanismo fúnebre; por outro, ao contrário, como límpida invocação de um mundo melhor, do triunfo da dignidade humana, da transformação das estruturas sociais. No evangelismo messiânico da lírica mendesiana podemos encontrar eco daquela catequese jesuítica da América Latina que produziu frutos também práticos, como a famosa república comunitária do Paraguai.

As duas palavras que aqui se opõem - pecado e evangelização - são colocadas em uma espécie de escala hierárquica de maior ou menor evidência na obra muriliana: a "obsessão do pecado" é a parte pessoal, sendo mais luminosa a esperança no "triunfo da dignidade humana", mantendo-se, portanto, dentro da esfera doutrinária tradicional do catolicismo. Em seguida surge a associação - e não será esta a única vez - com a experiência das missões jesuíticas setecentistas entre os índios guaranis no Paraguai como empreendimento revolucionário fracassado da Igreja Católica.

Surpreendente em si, tal associação nos revela alguns dos princípios norteadores de certa crítica, às voltas, consciente ou inconscientemente, com as discussões seculares sobre ser possível ou não uma civilização nos trópicos - o valor da literatura e seus autores como extensão da mesma questão -, opondo o Velho e o Novo Mundo, defendido por europeus ilustrados.

As palavras escolhidas por Jacobbi para apresentar Murilo, associando-o às atividades evangelizadoras dos jesuítas na América Latina, deixam transparecer o que em seus textos futuros será confirmado: o que move o olhar do crítico é o lugar possível de ser ocupado pelo poeta brasileiro - importante, sem dúvida, mas vindo de uma tradição quase ou nada conhecida, de um país por definição periférico, econômica e culturalmente, no quadro literário europeu e italiano. Pesa-lhe, por um lado, saber que nem a língua nem a literatura brasileiras servem-lhe de apoio para fazer notar o poeta estrangeiro; entretanto, o messianismo que encontra na poesia de Murilo Mendes confirma-lhe convicções pessoais, literárias, religiosas, políticas, já postas à prova na sua estadia no Brasil, mostrando-lhe um caminho a seguir nessa espécie de missão ética que unifica a voz do poeta à do crítico.

Na sequência do mesmo artigo, Jacobbi escreve:

Volto a pensar sobre essas coisas enquanto Murilo fala de sua vontade de paz e conciliação entre os homens, enquanto sua mulher, Maria da Saudade (ela também poeta e tradutora de Eliot) se informa sobre as últimas notícias do Brasil. Ismael Nery, Jorge [de Lima], Bernanos estão mortos, mas a voz de 
Murilo é bem viva. O sinal de sua desesperada paixão ética se faz sentir e se espalha pelo mundo atual.

Na aclimatação ao universo literário italiano o que Murilo diz, o que pensa não passará em branco, muito pelo contrário: entre autoimagens e imagens vai-se preparando o poeta libertário que receberá o importante prêmio Etna-Taormina em 1972. Mas esse caminho inclui a tessitura de outra imagem paralela, a do poeta europeu, já anunciada anteriormente por Stegagno Picchio e que aqui ressurge nas perguntas formuladas por Jacobbi: "O que este poeta poderá dizer à Europa? E o que a Europa poderá inspirar a seu canto?”

O contato direto de Murilo Mendes com os países europeus, em viagens realizadas a partir de 1952, passa a valer como elemento desencadeador de alterações da poética, sugerindo portanto estarmos diante de uma poesia de circunstância ou de viagem, apontando para o abandono da primeira poesia mais modernista ou instintiva por outra mais clássica, alimentada pela vivência europeia:

\footnotetext{
Murilo, portanto, antes no Rio, numa natural evolução, e depois na Europa, por evidentes reflexos de um mundo histórico e cultural mais rico de memórias e menos instintivo, foi aos poucos descobrindo - sem se trair ou se renegar um classicismo incomum.
}

A aproximação de Jacobbi a Stegagno Picchio torna perceptível em ambos, nesse momento, o esforço em definir algumas fronteiras na obra e na vida de Murilo que sejam capazes de inaugurar uma fase europeia para o poeta. Nos dois casos - mas também no de Chiocchio e de Puccini -, a contribuição do próprio Murilo Mendes não é desprezível. Nas conversas que o poeta manteve com os críticos e amigos com certeza terá sugerido um modo de ser visto e de ser lido - é crítico de si mesmo -, em contraste com as interpretações consagradas e na contramão delas. Tanto Stegagno Picchio como Jacobbi procuram frisar a distância que o Murilo atual mantém em relação ao primeiro Murilo - o dos poemaspiada, irreverente, modernista de primeira-hora -, substituindo-o por um poeta mais severo, mais clássico - o qual, se por um lado só é fiel à própria procura da poesia (que é sempre revelação) e à construção de uma poética própria (Stegagno Picchio), por outro é um humanista identificado com certa esquerda católica (Jacobbi).

Há ainda um último grupo de leitores especializados, e de peso, a ser considerado.

A coletânea de poemas organizada por Jacobbi Liricos brasileiros despertará a atenção de um leitor especial, o crítico Oreste Macrì, 
professor de Literatura e Língua Espanhola da Faculdade do Magistério, em Florença, a partir de 1954. Ao seu redor reuniram-se poetas e críticos. Foram extremamente ativos, organizando revistas, reunindo-se em grupos, escrevendo para jornais e revistas, na divulgação daquilo que hoje chamaríamos de uma perspectiva comparatista da literatura.

Oreste Macrì, Carlo Bo e Ruggero Jacobbi - ao lado de outros - são nomes que definem um universo crítico preciso: o da crítica e da teoria da poesia hermética, da poesia lírica moderna.

O elo que vincula críticos e poetas é a poesia moderna e o catolicismo, ou o espiritualismo encontrado a partir do catolicismo entendido como parte integrante do grande projeto civilizatório do Ocidente. Na verdade, é tamanha a crença no poder regenerador, renovador da poesia - a poesia pura por excelência, da alta tradição moderna europeia - que é possível ver nessa crítica também um princípio de fé, que unifica poesia e ética em defesa de grandes valores, entrevistos e propagados pela intensa discussão das formas da tradição da poesia, pelo menos até o momento das guerras.

Murilo Mendes pode ser incorporado pelos poetas e críticos que giram ao redor do grupo de Florença por ter sido identificado com os pressupostos - espírito religioso como fé, ideologia e poética - presentes tanto em Jacobbi, em Macrì e no grupo.

Uma das sínteses mais representativas dessa incorporação do poeta brasileiro ao grupo dos poetas católicos europeus foi escrita por Macrì em $1962^{8}$. Ao mesmo tempo em que constrói uma pequena genealogia da fortuna da poesia brasileira na Itália ${ }^{9}$, escreve sobre a poesia de Murilo Mendes. Diz Macrì:

\footnotetext{
Mendes [...] é um caso muito particular de poeta católico (de educação semítica) artisticamente empenhado contra as monstruosas antinomias do mundo contemporâneo das quais se faz continente representativo, intérprete e espectador imparcial e imperturbável. Parece uma contradição entre o empenho paulino de convertido e a imparcialidade do intelectual de fundo europeu; de fato, esta é a condição que Mendes impôs a si mesmo no seu
}

8 “Murilo Mendes poeta brasiliano", La Nazione, 1-3-1962; Ruggero Jacobbi - Oreste Macrí. Lettere 1941-1981, Roma: Bulzoni Editore, 1993, pp. 169-172.

9 Neste artigo não foram ainda citados dois elementos fundamentais da recepção italiana de Murilo Mendes: a publicação do livro Siciliana em 1959 e o prefácio ao livro, escrito por Ungaretti. Embora a importância do poeta italiano como divulgador da poesia brasileira na Itália seja inconteste - e Macrì frisa essa presença - o texto que abre Siciliana nos fala mais a respeito da poética ungarettiana e da sua visão do Brasil do que propriamente enfrenta a poesia de Murilo como faz Macrì. 
trabalho de quatro décadas: qualificar no mundo da graça paulina o mundo do número, da quantidade, da mecânica industrial, do capitalismo, do nazismo, da bomba atômica. Trata-se de uma experiência cristã agônica e de conflagração, distante tanto de Papini (ao qual já foi aproximado), quanto de Unamuno (a quem se aproxima na antinomia com o liberalismo). Em suma, não teme o Inimigo e o faz operar radicalmente em todos seus traços temporais e espaciais da matéria e do pecado original.

Macrì será um dos primeiros críticos a frisar a importância de se reconhecer um lugar especial para a leitura de certos textos religiosos ao se falar da poesia muriliana: São Paulo e São João, Mastro Eckhart, os teólogos beneditinos, Jorge de Lima, o ideólogo-artista Ismael Nery e os colaboradores da revista Esprit. Ao lado disso, ressalta a qualidade e valor da poesia muriliana aproximando de outros poetas reconhecidamente ímpares.

Seria possível pensar a um novo ímpeto místico romântico, no qual o poeta reserva para a poesia a função de 'conhecimento' e de 'transfiguração da condição humana'. De fato, a maior ambição dessa poesia é uma espécie de modernização técnico-expressiva do exemplo dos grandes poetas visionários: Dante, Hölderlin, Rimbaud, Fernando Pessoa. Modernização que implica em um tratamento especial - digamos cubista-surrealista-expressionista em sentido lato - dos universais míticos e simbólicos das Sagradas Escrituras e dos clássicos da teologia e da literatura espiritualista ocidental, no plano de um 'primitivismo da era atômica'.

Esse reconhecimento por parte de Macrì o induz a incluir Murilo Mendes no quadro maior da cultura europeia e, ao mesmo tempo, consolida a filiação do poeta ao catolicismo de alta estirpe que se confunde com a própria noção de "ocidente".

Mendes está no centro daquela inteligência católica europeia e portanto planetária, que já nos anos da belle époque entre as duas guerras pressentiu, corajosamente e contra duas frentes, os signos premonitórios do apocalipse bélico e pós-bélico, os signos positivos e negativos da futura 'universalidade', da 'planetização' dos fatos e das ideias, sobre o que o poeta discorre na sua autobiografia. Com uma carga emotiva, ameaçadora, subterrânea das fés populares...

Com esse artigo de Macrì encerra-se o que vem se denominando o momento inaugural da fortuna muriliana na Itália. Sua importância está, sem dúvida, em ter nomeado os passos dados pela crítica italiana em relação à poesia feita no Brasil, mas no caso da poesia de Murilo Mendes, o que torna o artigo de particular interesse é a enfática reivindicação 
dessa poesia como pertencente à tradição do pensamento católico ocidental. Portanto com Macrì a questão que surgira entre jornalistas, comentaristas e críticos, em particular no momento da primeiríssima recepção do poeta, é invertida: se Chiocchio, Puccini e Stegagno Picchio não pouparam esforços para desvincular o poeta de seu estigmatizante catolicismo, se Jacobbi associa-o á uma esquerda militante, o que justamente mais chama a atenção de Macrì é encontrar Murilo "no centro daquela inteligência católica europeia e portanto planetária”.

Palavras conclusivas que transpiram ainda a confiança em um projeto, que está, por exemplo, também em Auerbach, vive seus últimos estertores, o da ocidentalização do mundo através da literatura.

\section{REFERÊNCIAS BIBLIOGRÁFICAS}

BUCCIANTINI, Massimo. 2007. Italo Calvino e la scienza. Gli alfabeti del mondo. Roma: Donzelli.

JACOBBI, Ruggero. 196o. Lirici brasiliani dal modernismo ad oggi. Milano: Silva Editore/ Centro Europa-Americalatina del Collumbianum.

RAULINO, Berenice. 2002. Presença italiana no teatro brasileiro. São Paulo: Editora Perspectiva. 